\section{Safety and Efficacy of Dexmedetomidine, Ketofol, and Propofol for Sedation of Mechanically Ventilated Patients}

\section{Abstract}

Introduction: The Society of Critical Care Medicine recommended using non -benzodiazepine agents as propofol and dexmedetomidine for sedation of the critically ill patients in intensive care units.

Aims and Objectives: This study aimed to evaluate the safety and efficacy of ketofol, dexmedetomidine or propofol for sedation of postoperative mechanically ventilated patients in intensive care unit.

Materials and Methods: The study included ninety postoperative mechanically ventilated patients in the intensive care unit divided randomly into three equal groups.

Group A: 30 patients received ketofol an initial bolus dose $(500 \mathrm{mcg} / \mathrm{kg}$ ) of ketamine/propofol $1: 1$ (ketamine $8 \mathrm{mg} / \mathrm{mL}$ and propofol $8 \mathrm{mg} / \mathrm{mLl}$ followed by a maintenance dose of $(10 \mathrm{mcg} / \mathrm{kg} / \mathrm{min})$. Group B: 30 patients received loading dose infusion of dexmedetomidin diluted in $0.9 \%$ sodium chloride $1 \mathrm{mcg} / \mathrm{kg} / \mathrm{h}$ over $10 \mathrm{~min}$ followed by a maintenance infusion of $0.2-0.7 \mathrm{mcg} / \mathrm{kg} / \mathrm{h}$. Group C: 30 patients received propofol undiluted as an infusion of $1-3 \mathrm{mg} / \mathrm{kg} / \mathrm{h}$, after a loading dose infusion up to $1 \mathrm{mg} / \mathrm{kg}$ over $10 \mathrm{~min}$.

Sedation level, bispectral index, systolic and diastolic blood pressure, heart rate, recovery time, complications (hypertension, hypotension, bradycardia).

Result: RAMSY sedation score was statistically significantly higher in group A than group $B$ at the sixth and twelfth $h$; it was statistically significantly higher in group $A$ than group $C$ from the first to the twenty-fourth $h$ and was statistically significantly higher in group $B$ than group $C$ at first, the sixth and eighteenth $h$. The recovery time was longer in group A compared to group B and C, and it was statistically significant, no complications recorded in the three groups.

Conclusion: Using ketofol, dexmedetomidine or propofol was effective in maintaining sedation without hemodynamic complications in postoperative mechanically ventilated patients in the intensive care unit.

Keywords: Sedation; Ketofol; Dexmedetomidine; Propofol

\section{Samaa Rashwan*, Hatem El moutaz Mahmoud and Zeinab Taha}

\begin{abstract}
Department of Anesthesiology, Surgical ICU and Pain Management, Faculty of Medicine, Beni Suef University, 62511 Egypt
\end{abstract}

\section{*Corresponding author:}

Samaa Rashwan

झ samaarashwan1971@gmail.com

Department of Anesthesiology, Surgical ICU and Pain Management, Faculty of Medicine, Beni Suef University, 62511 Egypt

Tel: 00201270159125

Citation: Rashwan S, El moutaz Mahmoud $H$, Taha $Z$, et al. Safety and Efficacy of Dexmedetomidine, Ketofol, and Propofol for Sedation of Mechanically Ventilated Patients. J Intensive \& Crit Care Vol.4 No.4:16

Received: October 31, 2018; Accepted: December 13, 2018; Published: December 20, 2018

\section{Introduction}

The critically ill patients in an intensive care unit are exposed to different noxious stimuli including postoperative pain, multiple venipuncture, invasive monitoring, and endotracheal intubation; therefore they are usually managed using a continuous-infusion of sedative [1]. It has been recommended by the Society of Critical Care Medicine (SCCM) to use non-benzodiazepine agents as propofol and dexmedetomidine for sedation regimen [2]. This change from benzodiazepines to non-benzodiazepines is 
based on recent evidence reported that using benzodiazepine was an independent risk factor for the development of delirium, increased hospital Length of Stay (LOS) and increased 6-month mortality [3-7]. Alpha 2 agonist dexmedetomidine has sedative and analgesic effects and has been proved for ICU sedation for up to $24 \mathrm{~h}$. It provides hemodynamic stability without depressing respiration. It produces mild cognitive impairment allowing easy communication between the healthcare provider and the patient in the ICU. It also has the advantages of reducing the costs of ICU stay and more natural liberation from mechanical ventilation [8-10]. It has been reported that intravenous ketamine/propofol combination (ketofol) can be used for sedation for $24 \mathrm{~h}$ [11]. This is based on the finding that propofol is recommended for the short-term $(<24 \mathrm{~h})$ treatment of anxiety in the critically ill adult patients and continuous infusion doses of ketamine have also been described for $24 \mathrm{~h}$, so ketofol was expected to be given safely as a continuous infusion for $24 \mathrm{~h}$ [12], with the advantages of increasing their safety and efficacy and decreases their side effects [13].

In a study by Hamimy et al. continuous intravenous infusion of ketofol provided adequate and safe short-term sedation (less than $24 \mathrm{~h}$ ) for critically ill patients in the intensive care units, rapid recovery without significant complications but because of the small size of their case series further studies with more significant number of patients were recommended to confirm their finding [14].

This study aimed to evaluate the safety and efficacy of using ketofol compared to dexmedetomidine or propofol for sedation of postoperative patients who required mechanical ventilation in the intensive care unit.

\section{Materials and Methods}

This study was conducted in the Surgical Intensive Care Unit (SICU) of Beni-Suef University hospital; the study was registered at PACRT (trial registration number 201803003203136) after obtaining approval from the anesthesia department and the local committee of ethics and research (The FM-BSU REC) and obtaining consents from the patients or their guardians. This study was performed from 21 November 2015 to 21 November 2017.

The study included ninety postoperative adult patients of both sex (aged 18-65 years old) who required close monitoring and mechanical ventilation and sedation for $24 \mathrm{~h}$ after major surgery, excluding pregnant females, history of epilepsy and patients with increased intracranial tension, major renal, hepatic or cardiac diseases, neurosurgical operations or having allergies to the studied drugs. On arrival to the SICU the patients were connected to mechanical ventilator (initial sitting were SIMV mode, $\mathrm{FiO}_{2} 40 \%$, PEEP 5-8 $\mathrm{cm} \mathrm{H}_{2} \mathrm{O}$, pressure support 10-15 $\mathrm{Cm} \mathrm{H}_{2} \mathrm{O}$ ), monitoring were applied ( 5 leads ECG, pulse oximetry, capnography, invasive and noninvasive arterial blood pressure, and central venous pressure were monitored), BIS electrodes were applied to the forehead. 12 leads ECG, chest X-ray were done; a blood sample was taken for complete blood count, biochemistry and arterial blood gas analysis. The patients were randomly divided into three equal groups according to closed, opaque envelop technique (30 patients each):

Group A: 30 patients received ketofol an initial bolus dose (500 $\mathrm{mcg} / \mathrm{kg}$ ) of ketamine/propofol $1: 1$ (ketamine $8 \mathrm{mg} / \mathrm{ml}$ and propofol $8 \mathrm{mg} / \mathrm{mL}$ followed by a maintenance dose of (10 mcg/ $\mathrm{kg} / \mathrm{min}$ ) [14].

Group B: 30 patients received loading dose infusion of dexmedetomidine (precedex, Hospira inc lake forest, IL60045 US) diluted in $0.9 \%$ sodium chloride $1 \mathrm{mcg} / \mathrm{kg} / \mathrm{h}$ over $10 \mathrm{~min}$ followed by a maintenance infusion of $0.2-0.7 \mathrm{mcg} / \mathrm{kg} / \mathrm{h}$ [15].

Group C: 30 patients received propofol (diprivan;Fresenius Kabi Astaria GmbH-A8005Gra kz, Austaria) undiluted as an infusion of $1-3 \mathrm{mg} / \mathrm{kg} / \mathrm{h}$, after a loading dose infusion up to $1 \mathrm{mg} / \mathrm{kg}$ over 10 $\min$.

\section{The following data were collected and recorded by SICU staff unaware of the study protocol}

1. Demographic data (age, sex, weight) and types of surgeries.

2. Degree of sedation was recorded hourly for $24 \mathrm{~h}$ using the Ramsay sedation score (16) and continuously using the bispectral index, and the sedation level was maintained at RSS $>2$ by adjustment of the drug infusion rate, as a primary outcome.

3. Systolic Blood Pressure (SBP), Diastolic Blood Pressure (DBP) and Heart Rate (HR).

4. Recovery time: the time required for the patient to regain the conscious level before sedation) after discontinuing sedation [16].

5. Complications including hypotension which is defined as (systolic blood pressure less than $90 \mathrm{mmHg}$ ), hypertension which is defined as systolic blood pressure more than $160 \mathrm{mmHg}$, bradycardia (heart rate less than 60 beats/ minute), and tachycardia (heart rate more than 90 beats/ minute) were also recorded. Hypotension was managed by lowering the infusion rate of sedation and IV bolus of crystalloid fluid; hypertensive events were achieved by increasing the sedation infusion rate till stabilizing the blood pressure then the infusion rate was adjusted according to the study protocol.

Inadequate analgesia was expected if the patient experienced tachycardia or hypertension $>20 \%$ from the baseline reading in spite of adequate sedation level as indicated by BIS value, so fentanyl (25-50 $\mu \mathrm{g}$ IV bolus) was given.

\section{Statistical analysis}

\section{Sample size}

After a pilot study with five patients in each group, the minimum detectable difference in RSS between groups was 0.8 , and a standard deviation of residuals was 0.7 . Accordingly, the calculated 
minimum sample size was 24 patients in each group with $95 \%$ power and $\alpha$ level was 0.05 using F-test (ANOVA), Biostatstics, version3.01.The number was increased to 30 patients in each group in case of the drop in any case.

\section{Statistical methods}

All statistical calculations were done using computer programs Microsoft Excel (Microsoft Corporation, NY, USA) \& SPSS (Statistical Package for the social science) statistical programs (SPSS Inc., Chicago, IL, USA). Data were statistically described in terms of mean \pm standard deviation (SD), median (range) or number (percentage) as appropriate.

Inferential analyses were done for quantitative variables using paired T-test or one way ANOVA. P-values less than 0.05 were considered significant and $p$ values less than 0.01 were considered highly significant.

\section{Results}

All cases completed the study, Figure 1.
Table 1 showed the types of surgeries

No statistically significant differences in the demographic data between the studied groups ( $p$ value $>0.05$ ); (Table 2).

Systolic Blood Pressure (SBP), diastolic Blood Pressure (DBP) and Heart Rate (HR) were recorded before starting sedation, then after starting sedation by $30 \mathrm{~min}$, then hourly for $24 \mathrm{~h}$, but for statistical analysis the data were averaged and recorded at $6 \mathrm{~h}$ interval.

The heart rate was higher in group $A$ than group $B$ and $C$ before starting sedation, but it was not statistically significant $(p>0.05)$, the heart rate was statistically significantly higher in group $A$ than both group B and C 30 min after starting sedation and at sixth, twelfth, eighteenth and twenty-fourth $h(p<0.001)$, it was also statistically significantly higher in group $C$ than group $B 30$ min after starting sedation and at sixth, twelfth, eighteenth and twenty-fourth $h(p<0.001)$ (Table 3).

The systolic arterial blood pressure was statistically significantly higher in group A than both group B and C 30 min after starting sedation, and at sixth, twelfth, eighteenth and twenty-fourth $h$,

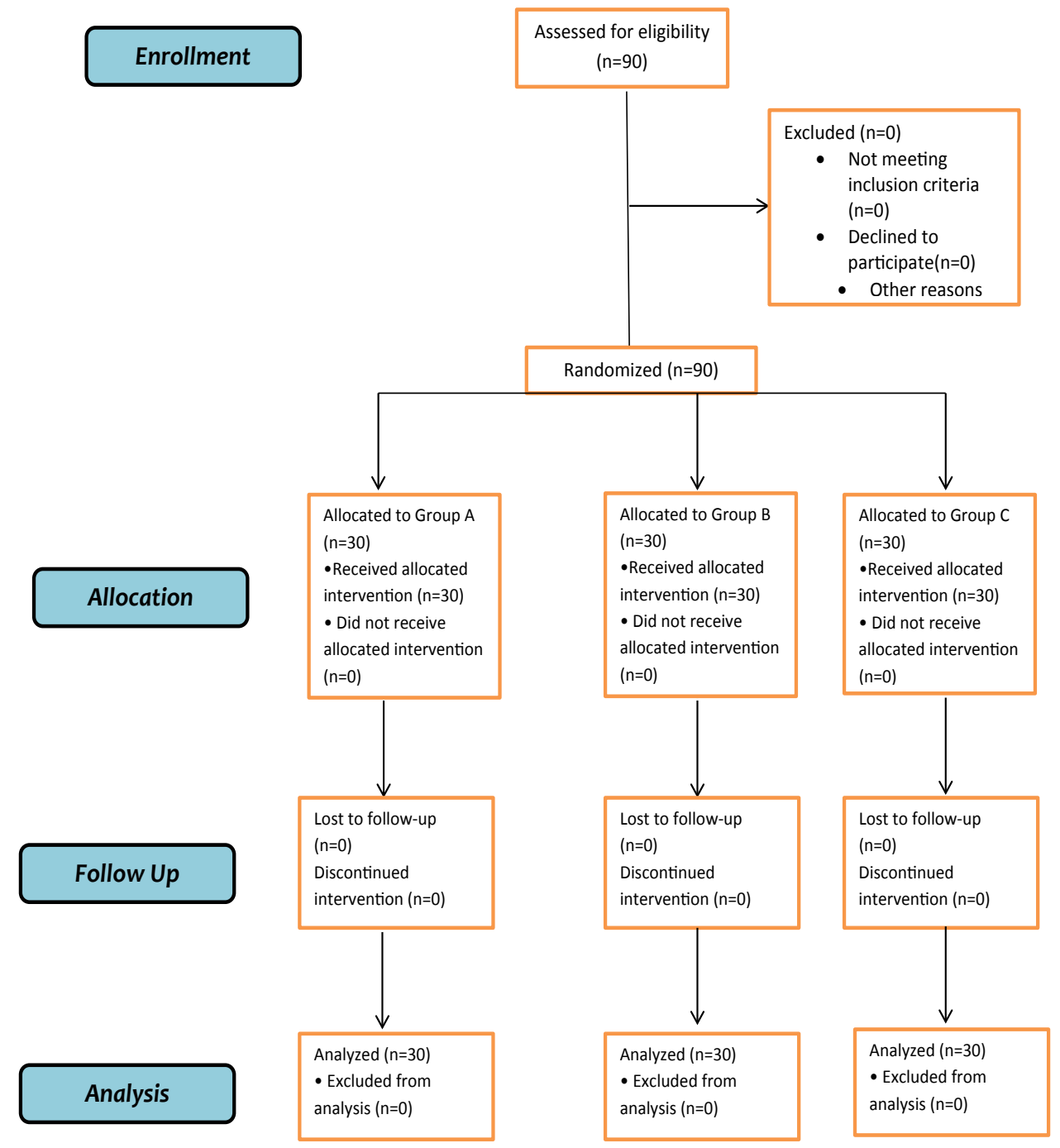

Figure 1 Consort flow participant diagram. 
Table 1 Types of surgeries.

Group A (Ketofol group), Group B (Dexmedetomidine group), Group C (Propofol group).

Data are presented as numbers (\%)

\begin{tabular}{|l|c|c|c|}
\hline Types of surgeries (no \%) & Group A (n=30) & Group B (n=30) & Group C (n=30) \\
\hline Cesarean hysterectomy & $8(26.6)$ & $9(30)$ & $8(26.6)$ \\
\hline Radical cystectomy & $5(16.6)$ & $3(10)$ & $5(16.6)$ \\
\hline Abdominal Exploration & $7(23.3)$ & $8(26.6)$ & $4(13.3)$ \\
\hline Amputation & $8(26.6)$ & $5(16.6)$ & $4(13.3)$ \\
\hline Embolectomy & $0(0)$ & $2(6.6)$ & $3(10)$ \\
\hline Fixation of fractured femur & $2(6.6)$ & $1(3.3)$ & $3(10)$ \\
\hline Fixation of cervical spine & $0(0)$ & $2(6.6)$ & $2(6.6)$ \\
\hline Fixation of dorsal spine & $0(0)$ & $0(0)$ & $1(3.3)$ \\
\hline
\end{tabular}

Table 2 Demographic data of the three groups.

Group A (Ketofol group), Group B (Dexmedetomidine group), Group C (Propofol group).

Data were presented as mean $\pm S D$ and number (percentage), $p<0.05$ is considered significant

\begin{tabular}{|l|c|c|c|c|}
\hline \multicolumn{1}{|c|}{ Variable } & Group A (n=30) & Group B (n=30) & Group C (n=30) & p value \\
\hline Age (year) & $34.6 \pm 18.0$ & $35.5 \pm 14.7$ & $40.2 \pm 13.4$ & 0.329 \\
\hline Weight (kg) & $67.7 \pm 5.0$ & $66.1 \pm 7.7$ & $68.5 \pm 5.4$ & 0.303 \\
\hline Sex, no. (\%) & & & & \\
\hline - Male & $18(60)$ & $20(66.7)$ & $19(63.3)$ & 0.868 \\
\hline$\quad$ Female & $12(40)$ & $10(33.3)$ & $11(36.7)$ & \\
\hline
\end{tabular}

Table 3 Heart rate (Bpm).

Group A (Ketofol group), Group B (Dexmedetomidine group), Group C (Propofol group).

Data were presented as mean \pm SD.

$p$ value $<0.05$ were considered significant and $P$ values $<0.01$ were considered highly significant.

$p 1: p$ value of comparison between group $A$ and $B$.

$p 2: p$ value of comparison between group $A$ and $C$.

p3: $p$ value of comparison between group $B$ and $C$.

\begin{tabular}{|c|c|c|c|c|}
\hline Time & Group A $(n=30)$ & Group B $(n=30)$ & Group C $(n=30)$ & $p$ value \\
\hline \multirow{3}{*}{ Before sedation } & \multirow{3}{*}{$106.5 \pm 8.1$} & \multirow{3}{*}{$103.2 \pm 11.2$} & \multirow{3}{*}{$101.1 \pm 23.9$} & $p_{1}=0.419$ \\
\hline & & & & $P_{2}=0.192$ \\
\hline & & & & $p_{3}=0.616$ \\
\hline \multirow{3}{*}{$30 \mathrm{~min}$ after sedation } & \multirow{3}{*}{$90.4 \pm 1.7$} & \multirow{3}{*}{$66.2 \pm 1.3$} & \multirow{3}{*}{$84.5 \pm 1.3$} & $\mathrm{p}_{1}<0.001$ \\
\hline & & & & $\mathrm{p}_{2}<0.001$ \\
\hline & & & & $p_{3}<0.001$ \\
\hline \multirow{3}{*}{$6^{\text {th }} \mathbf{h}$ after sedation } & \multirow{3}{*}{$91.1 \pm 1.6$} & \multirow{3}{*}{$63.6 \pm 1.2$} & \multirow{3}{*}{$83.3 \pm 1.2$} & $\mathrm{p}_{1}<0.001$ \\
\hline & & & & $p_{2}<0.001$ \\
\hline & & & & $p_{3}<0.001$ \\
\hline \multirow{3}{*}{$12^{\text {th }} h$ after sedation } & \multirow{3}{*}{$91.1 \pm 1.9$} & \multirow{3}{*}{$62.8 . \pm 1.8$} & \multirow{3}{*}{$85.7 \pm 1.6$} & $\mathrm{p}_{1}<0.001$ \\
\hline & & & & $p_{2}<0.001$ \\
\hline & & & & $p_{3}<0.001$ \\
\hline \multirow{3}{*}{$18^{\text {th }} h$ after sedation } & \multirow{3}{*}{$92.3 \pm 2.3$} & \multirow{3}{*}{$61.1 \pm 1.6$} & \multirow{3}{*}{$82.2 \pm 1.7$} & $p_{1}<0.001$ \\
\hline & & & & $p_{2}<0.001$ \\
\hline & & & & $p_{3}<0.001$ \\
\hline \multirow{3}{*}{$24^{\text {th }} h$ after sedation } & \multirow{3}{*}{$91.4 \pm 1.5$} & \multirow{3}{*}{$62.3 \pm 1.3$} & \multirow{3}{*}{$82.6 \pm 1.6$} & $p_{1}<0.001$ \\
\hline & & & & $p_{2}<0.001$ \\
\hline & & & & $\mathrm{p}_{3}<0.001$ \\
\hline
\end{tabular}

$(p<0.001)$, it was also statistically significantly higher in group $B$ than C 30 min after starting sedation and at sixth, twelfth, eighteenth and twenty-fourth $h(p<0.001)$ (Table 4).

The Diastolic Blood Pressure (DBP) was statistically significantly higher in group $A$ than group $B$ and $C$ from the first to the $24^{\text {th }} \mathrm{h}$,
DBP was statistically significantly higher in group B than C 30 min after starting sedation and at the sixth, twelfth, eighteenth and twenty-fourth $h(p<0.001)$ (Table 5).

BIS value was statistically significantly higher in group $A$ than group $B$ at sixth $h$ only $(p<0.01)$. It was statistically significantly 
Table 4 Systolic arterial blood pressure $(\mathrm{mmHg})$.

Group A (Ketofol group), Group B (Dexmedetomidine group), Group C (Propofol group).

Data were presented as mean \pm SD.

$p$ values less than 0.05 were considered significant and $P$ values less than 0.01 were considered highly significant.

$p 1: p$ value of comparison between group $A$ and $B$.

p2: $p$ value of comparison between group $A$ and $C$.

$p 3$ : $p$ value of comparison between group $B$ and $C$.

\begin{tabular}{|c|c|c|c|c|}
\hline Time & Group A $(n=30)$ & Group B $(n=30)$ & Group C $(n=30)$ & $p$ value \\
\hline \multirow{3}{*}{ Before sedation } & \multirow{3}{*}{$135.4 \pm 4.3$} & \multirow{3}{*}{$134.7 \pm 4.7$} & \multirow{3}{*}{$136 \pm 6.5$} & $\mathrm{p} 1=0.26$ \\
\hline & & & & $\mathrm{p} 2=0.33$ \\
\hline & & & & $p 3=0.18$ \\
\hline \multirow{3}{*}{$30 \mathrm{~min}$ after sedation } & \multirow{3}{*}{$124.3 \pm 4.2$} & \multirow{3}{*}{$114.6 \pm 3.6$} & \multirow{3}{*}{$103.6 \pm 4.1$} & $\mathrm{p} 1=0.001$ \\
\hline & & & & $\mathrm{p} 2=0.001$ \\
\hline & & & & $p 3=0.001$ \\
\hline \multirow{3}{*}{$6^{\text {th }} \mathrm{h}$ after sedation } & \multirow{3}{*}{$124.5 \pm 6.2$} & \multirow{3}{*}{$111.5 \pm 4.8$} & \multirow{3}{*}{$102.8 \pm 2.2$} & $\mathrm{p} 1=0.001$ \\
\hline & & & & $p 2=0.001$ \\
\hline & & & & p3 $=0.001$ \\
\hline \multirow{3}{*}{$12^{\text {th }} \mathrm{h}$ after sedation } & \multirow{3}{*}{$125.8 \pm 6.4$} & \multirow{3}{*}{$114.2 \pm 3.5$} & \multirow{3}{*}{$103.9 \pm 2.8$} & $\mathrm{p} 1=0.001$ \\
\hline & & & & $\mathrm{p} 2=0.001$ \\
\hline & & & & $p 3=0.001$ \\
\hline \multirow{3}{*}{$18^{\text {th }} \mathrm{h}$ after sedation } & \multirow{3}{*}{$126.2 \pm 4.7$} & \multirow{3}{*}{$112.9 \pm 3.7$} & \multirow{3}{*}{$103.1 \pm 3.9$} & $\mathrm{p} 1=0.001$ \\
\hline & & & & $\mathrm{p} 2=0.001$ \\
\hline & & & & $p 3=0.001$ \\
\hline \multirow{3}{*}{$24^{\text {th }} \mathrm{h}$ after sedation } & \multirow{3}{*}{$127.4 \pm 5.6$} & \multirow{3}{*}{$113.1 \pm 4.5$} & \multirow{3}{*}{$104.5 \pm 4.3$} & $\mathrm{p} 1=0.001$ \\
\hline & & & & $\mathrm{p} 2=0.001$ \\
\hline & & & & $p 3=0.001$ \\
\hline
\end{tabular}

Table 5 Diastolic arterial blood pressure $(\mathrm{mmHg})$

Group A (Ketofol group), Group B (Dexmedetomidine group), Group C (Propofol group).

Data were presented as mean \pm SD.

$p$ values less than 0.05 were considered significant and $P$ values less than 0.01 were considered highly significant.

$p 1: p$ value of comparison between group $A$ and $B$.

$p 2$ : $p$ value of comparison between group $A$ and $C$.

$p 3$ : $p$ value of comparison between group $B$ and $C$

\begin{tabular}{|c|c|c|c|c|}
\hline Time & Group A $(n=30)$ & Group B $(n=30)$ & Group C $(n=30)$ & $p$ value \\
\hline \multirow{3}{*}{ Before sedation } & \multirow{3}{*}{$79.7 \pm 1.3$} & \multirow{3}{*}{$80.3 \pm 3$} & \multirow{3}{*}{$79.8 \pm 2$} & $\mathrm{p} 1=0.16$ \\
\hline & & & & $\mathrm{p} 2=0.33$ \\
\hline & & & & p3 $=0.27$ \\
\hline \multirow{3}{*}{$30 \mathrm{~min}$ after sedation } & \multirow{3}{*}{$74.7 \pm 1.3$} & \multirow{3}{*}{$69.5 \pm 1$} & \multirow{3}{*}{$58.2 \pm 0.8$} & $\mathrm{p} 1=0.001$ \\
\hline & & & & $\mathrm{p} 2=0.001$ \\
\hline & & & & p3 $=0.001$ \\
\hline \multirow{3}{*}{$6^{\text {th }} \mathrm{h}$ after sedation } & \multirow{3}{*}{$75.8 \pm 1.2$} & \multirow{3}{*}{$68 \pm 0.8$} & \multirow{3}{*}{$57.1 \pm 0.8$} & $\mathrm{p} 1=0.001$ \\
\hline & & & & $\mathrm{p} 2=0.001$ \\
\hline & & & & p3 $=0.001$ \\
\hline \multirow{3}{*}{$12^{\text {th }} \mathrm{h}$ after sedation } & \multirow{3}{*}{$73.5 \pm 1.1$} & \multirow{3}{*}{$65.5 \pm 1.3$} & \multirow{3}{*}{$58.4 \pm 1.4$} & $\mathrm{p} 1=0.001$ \\
\hline & & & & $\mathrm{p} 2=0.001$ \\
\hline & & & & p3 $=0.001$ \\
\hline \multirow{3}{*}{$18^{\text {th }} h$ after sedation } & \multirow{3}{*}{$73.4 \pm 1.2$} & \multirow{3}{*}{$62.1 \pm 0.9$} & \multirow{3}{*}{$58.4 \pm 1.3$} & $\mathrm{p} 1=0.001$ \\
\hline & & & & $\mathrm{p} 2=0.001$ \\
\hline & & & & p3 $=0.001$ \\
\hline \multirow{3}{*}{$24^{\text {th }} h$ after sedation } & \multirow{3}{*}{$75.5 \pm 0.8$} & \multirow{3}{*}{$63 \pm 0.8$} & \multirow{3}{*}{$58.8 \pm 1$} & $\mathrm{p} 1=0.001$ \\
\hline & & & & $\mathrm{p} 2=0.001$ \\
\hline & & & & $p 3=0.001$ \\
\hline
\end{tabular}

higher in group $A$ than group $C$ at first and eighteenth $h(p<0.01)$, and was statistically significantly higher in group $B$ than group $C$ from the first to $24 \mathrm{~h}(\mathrm{p}<0.01)$ (Table 6).
RAMSY sedation score was statistically significantly higher in group $A$ than group $B$ at sixth and twelfth $h$, it was statistically significantly higher in group $A$ than group $C$ in the first, sixth and eighteenth $h$, it was statistically significantly higher in group $B$ 
Table 6 Bispectral index (BIS).

Group A (Ketofol group), Group B (Dexmedetomidine group), Group C (Propofol group).

Data were presented as mean \pm SD.

$p$ values $<0.05$ were considered significant and $P$ values $<0.01$ were considered highly significant.

$p 1: p$ value of comparison between group $A$ and $B$.

p2: $p$ value of comparison between group $A$ and $C$.

$p 3$ : $p$ value of comparison between group $B$ and $C$.

\begin{tabular}{|c|c|c|c|c|}
\hline BIS & Group A $(n=30)$ & Group B $(n=30)$ & Group C $(n=30)$ & p-value \\
\hline \multirow{3}{*}{$1^{\text {st }} h$} & \multirow{3}{*}{$76.6 \pm 2.7$} & \multirow{3}{*}{$76.8 \pm 3.9$} & \multirow{3}{*}{$72.7 \pm 3.2$} & $\mathrm{p} 1=0.846$ \\
\hline & & & & $\mathrm{p} 2=0.001$ \\
\hline & & & & $p 3=0.001$ \\
\hline \multirow{3}{*}{$6^{\text {th }} h$} & \multirow{3}{*}{$74.8 \pm 3.1$} & \multirow{3}{*}{$76.7 \pm 3.5$} & \multirow{3}{*}{$73.2 \pm 4.0$} & $\mathrm{p} 1=0.037$ \\
\hline & & & & $\mathrm{p} 2=0.090$ \\
\hline & & & & $p 3=0.001$ \\
\hline \multirow{3}{*}{$12^{\text {th }} h$} & \multirow{3}{*}{$74.7 \pm 3.5$} & \multirow{3}{*}{$76.3 \pm 3.0$} & \multirow{3}{*}{$73.6 \pm 3.5$} & $\mathrm{p} 1=0.059$ \\
\hline & & & & $\mathrm{p} 2=0.210$ \\
\hline & & & & $\mathrm{p} 3=0.002$ \\
\hline \multirow{3}{*}{$18^{\text {th }} h$} & \multirow{3}{*}{$75.1 \pm 3.3$} & \multirow{3}{*}{$76.2 \pm 3.4$} & \multirow{3}{*}{$72.3 \pm 3.4$} & $\mathrm{p} 1=0.209$ \\
\hline & & & & $\mathrm{p} 2=0.002$ \\
\hline & & & & $p 3=0.001$ \\
\hline \multirow{3}{*}{$24^{\text {th }} h$} & \multirow{3}{*}{$74.4 \pm 2.9$} & \multirow{3}{*}{$75.5 \pm 2.8$} & \multirow{3}{*}{$72.7 \pm 4.2$} & $\mathrm{p} 1=0.196$ \\
\hline & & & & $\mathrm{p} 2=0.064$ \\
\hline & & & & $\mathrm{p} 3=0.002$ \\
\hline
\end{tabular}

Table 7 Ramsay sedation score.

Group A (Ketofol group), Group B (Dexmedetomidine group), Group C (Propofol group).

Data were presented as median (range).

$p$ values $<0.05$ were considered significant and $P$ values $<0.01$ were considered highly significant.

$p 1$ : $p$ value of comparison between group $A$ and $B$.

$p 2: p$ value of comparison between group $A$ and $C$.

p3: $p$ value of comparison between group $B$ and $C$.

\begin{tabular}{|c|c|c|c|c|}
\hline RAMSY scoring system & Group A $(n=30)$ & Group B $(n=30)$ & Group C $(n=30)$ & $p$ value \\
\hline \multirow{3}{*}{$1^{\text {st }} h$} & \multirow{3}{*}{$3(2-4)$} & \multirow{3}{*}{$3(2-4)$} & \multirow{3}{*}{$3(2-5)$} & $\mathrm{p} 1=0.397$ \\
\hline & & & & $\mathrm{p} 2=0.0001$ \\
\hline & & & & $\mathrm{p} 3=0.0001$ \\
\hline \multirow{3}{*}{$6^{\text {th }} h$} & \multirow{3}{*}{$3(2-4)$} & \multirow{3}{*}{$3(2-4)$} & \multirow{3}{*}{$3(3-5)$} & $\mathrm{p} 1=0.022$ \\
\hline & & & & $\mathrm{p} 2=0.028$ \\
\hline & & & & $\mathrm{p} 3=0.003$ \\
\hline \multirow{3}{*}{$12^{\text {th }} h$} & \multirow{3}{*}{$3(2-4)$} & \multirow{3}{*}{$3(2-4)$} & \multirow{3}{*}{$3(3-5)$} & $\mathrm{p} 1=0.006$ \\
\hline & & & & $\mathrm{p} 2=0.179$ \\
\hline & & & & $p 3=0.001$ \\
\hline \multirow{3}{*}{$18^{\text {th }} h$} & \multirow{3}{*}{$3(2-4)$} & \multirow{3}{*}{$3(2-4)$} & \multirow{3}{*}{$3(3-5)$} & $\mathrm{p} 1=0.306$ \\
\hline & & & & $\mathrm{p} 2=0.0009$ \\
\hline & & & & $\mathrm{p} 3=0.0009$ \\
\hline \multirow{3}{*}{$24^{\text {th }} h$} & \multirow{3}{*}{$3(2-4)$} & \multirow{3}{*}{$3(2-4)$} & \multirow{3}{*}{$3(3-5)$} & $\mathrm{p} 1=0.085$ \\
\hline & & & & $\mathrm{p} 2=0.120$ \\
\hline & & & & p3 $=0.011$ \\
\hline
\end{tabular}

than group C from the first to twenty-fourth h (Table 7).

The recovery time was longer in group A compared to group $B$ and $C$, and it was statistically significant $(p<0.05)$ (Table 8).

The mean administered dosages of fentanyl was $382.3 \pm 9.7 \mu \mathrm{g}$, $349.8 \pm 7.5 \mu \mathrm{g}, 439.7 \pm 12.3 \mu \mathrm{g}$ for groups $\mathrm{A}-\mathrm{C}$ respectively, it was statistically significantly higher in group $C$ than group $A$ and $B$ group $(p<0.001)$, and it was statistically significantly higher in group A than in B group ( $<<0.001)$ (Table 9).

\section{Discussion}

The current study showed that infusion of ketofol, dexmedetomidine or propofol was effective for sedation of mechanically ventilated patients in SICU as detected by RSS which is maintained in the range of 2-4 for the patients who were sedated by ketofol or dexmedetomidine and 2-5 for the patients who were sedated by propofol without causing hemodynamic complications. Dexmedetomidine group required less fentanyl for postoperative analgesia. 
Table 8 Recovery time (min).

Group A (Ketofol group), Group B (Dexmedetomidine group), Group C (Propofol group).

Data were presented as mean \pm SD.

$p$ values $<0.05$ were considered significant and $P$ values $<0.01$ were considered highly significant.

$p 1: p$ value of comparison between group $A$ and $B$.

p2: $p$ value of comparison between group $A$ and $C$.

$p 3$ : $p$ value of comparison between group $B$ and $C$.

\begin{tabular}{|l|c|c|c|c|}
\hline & Group A $(\mathbf{n = 3 0})$ & Group B $(\mathbf{n = 3 0})$ & Group C $(\mathbf{n = 3 0})$ & $p 1=0.038$ \\
\hline Recovery time (min.) & $35.8 \pm 14.4$ & $29.5 \pm 10.9$ & $27.7 \pm 8.6$ & $p 2=0.038$ \\
\hline
\end{tabular}

Table 9 Fentanyl requirement $(\mu \mathrm{g})$.

Group A (Ketofol group), Group B (Dexmedetomidine group), Group C (Propofol group).

Data were presented as mean \pm SD.

$p$ values $<0.05$ were considered significant and $P$ values $<0.01$ were considered highly significant.

$p 1$ : $p$ value of comparison between group $A$ and $B$.

$p 2$ : $p$ value of comparison between group $A$ and $C$.

p3: $p$ value of comparison between group $B$ and $C$.

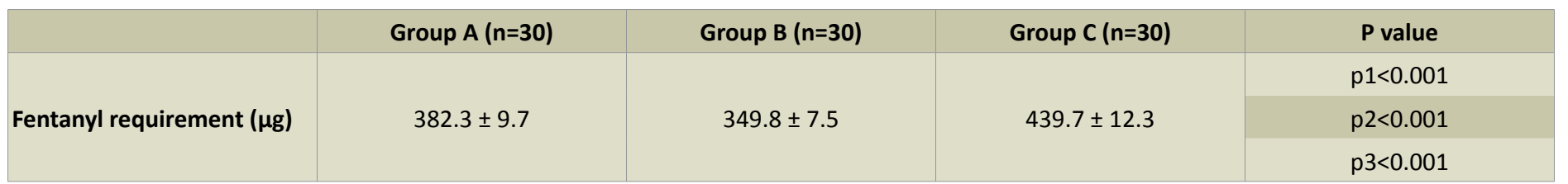

There are few available data in the scientific literature for using ketofol for sedating the patients in ICUs but there are several trials used ketofol for procedural sedation. The result of this study coincides with those of the study which was performed by Hamimy et al. [14]. They concluded that using ketofol for sedating the mechanically ventilated patients was effective in maintaining Ramsay sedation score of 4 without hemodynamic instability.

Willman [17] and Andolfatto [18] concluded that none of the patients developed hypotension when ketofol was administrated in a mean dose of $(0.75 \mathrm{mg} / \mathrm{kg}$ of ketamine and $0.75 \mathrm{mg} / \mathrm{kg}$ of propofol) but they reported in another study that only 1 patient out of 728 patients became hypotensive when ketofol was used for PSA for orthopedic procedures. Dal et al. [19] concluded that ketofol was effective and safe for sedation during endobronchial ultrasound-guided needle aspiration procedure.

Ghadami et al. [20] reported that quality of sedation, the total dose of the drug and respiratory and hemodynamic parameters were comparable when using two different ratios of ketofol in 60 pediatric patients scheduled for lumbar puncture or bone marrow aspiration. David et al. [21] did not report a significant difference in respiratory depression between 98 adults and 93 children.

Tosun et al. [22] demonstrated that ketofol was useful for sedation and providing hemodynamic stability in pediatric patients who underwent upper GIE procedures.

On the other hand, Loh et al. [23] reported that fewer patients who were given ketofol had a significant hemodynamic compromise, and required active interventions using fluid or vasopressor. They explained their results by the opposite effect of ketamine and propofol on the autonomic nervous system, as ketamine is sympathomimetic, but propofol lessens this effect.
One study was done by Venn et al. [24] which included 20 adult patients who required at least $8 \mathrm{~h}$ of postoperative mechanical ventilation, the patients who were sedated by dexmedetomidine significantly needed less alfentanil ( $2.5 \mathrm{vs} .0 .8 \mathrm{mg} . \mathrm{h}^{-1}$ ) than those sedated by propofol. RSS for propofol was $5[4,5]$, and for dexmedetomidine, RSS was 5 [4-6]. In the current study, RSS was 2-4 for dexmedetomidine and 2-5 for the patients who were sedated by propofol; the difference between this study and the study of Venn et al. may be explained by different time for assessing the BIS value as this study was for $24 \mathrm{~h}$ and the study of Venn et al. [24] was for $8 \mathrm{~h}$, also due to different number of the patients between the two studies.

In a study by Prerana et al. [25] that included thirty patients who required postoperative mechanical ventilation and sedation; 15 patients received dexmedetomidine, and 15 patients received propofol. The mean pulse-rate, respiratory rate, blood pressure between the groups was not statistically significant. The mean RSS was between 2-4 and 2-3 for dexmedetomidine and propofol groups respectively.

In this study, Ramsay sedation score was 2-4 and 2-5 for dexmedetomidine group and propofol group respectively. These results were not in line with the study by Corbett et al. [26] they titrated dexmedetomidine or propofol to a Ramsay sedation score of 3-4.

Demiraran et al. [27] did not find a difference in $\mathrm{HR}$, mean arterial pressure, or recovery time in a prospective trial of 50 patients underwent upper endoscopy sedated with dexmedetomidine or midazolam.

Stephan et al. [28] reported that ICU patients receiving prolonged mechanical ventilation, dexmedetomidine was comparable 
to midazolam and propofol in maintaining light to moderate sedation. In the current study the recovery time was $35.8 \pm 14.4$ min for the patients sedated by ketofol $29.5 \pm 10.9 \mathrm{~min}$ for the patients sedated by dexmedetomidine and it was $27.7 \pm 8.6 \mathrm{~min}$ for the patients who were sedated by propofol, while in the study of Hamimy et al. [14] the median recovery time was $30 \mathrm{~min}$ (range 18-60 $\mathrm{min}$ ) and in the study of Andolfatto et al. [17] the median recovery time was $14 \mathrm{~min}$ (range 3-50 $\mathrm{min}$ ). The different number of patients may explain the difference between this study and other studies, and they used ketofol while in this study included three groups of patients sedated by ketofol, dexmedetomidine or propofol, and Andolfatto et al. [17] used ketofol for procedural sedation.

In this study, the patients sedated by dexmedetomidine required less fentanyl than patients sedated by ketofol or propofol. This was also reported by Vinit et al. [29].

\section{References}

1 Lonardo NW, Mone MC, Nirula R, Kimball EJ, Ludwig K, et al. (2014) The propofol is associated with favorable outcomes compared with benzodiazepines in ventilated intensive care unit patient. Am J Respir Crit Care Med 189: 1383-1394.

2 Barr J, Fraser GL, Puntillo K, Ely EW, Gelinas C, et al. (2013) Clinical practice guidelines for the management of pain, agitation, and delirium in adult patients in the intensive care unit. Crit Care Med 41: 263-306.

3 Girard TD, Jackson JC, Pandharipande PP, Pun BT, Thompson $\mathrm{JL}$, et al. (2010) Delirium as a predictor of long-term cognitive impairment in survivors of critical illness. Crit Care Med 38 : 1513-1520.

4 Ely EW, Shintani A, Truman B, Speroff T, Gordon SM, et al. (2004) Delirium as a predictor of mortalityin mechanically ventilated patients in the intensive care unit. JAMA 291: 1753-1762.

5 Pandharipande P, Shintani A, Peterson J, Pun BT, Wilkinson $\mathrm{GR}$, et al. (2006) Lorazepam is an independent risk factor for transitioning to delirium in intensive care unit patients. Anesthesiology 104: 21-26.

6 Carson SS, Kress JP, Rodgers JE, Vinayak A, Campbell-Bright $S$, et al. (2006) A randomized trial of intermittent lorazepam versus propofol with daily interruption in mechanically ventilated patients. Crit Care Med 34: 1326-1332.

7 Shehabi Y, Riker RR, Bokesch PM, Wisemandle W, Shintani A, et al. (2010) Delirium duration and mortality inlightly sedated, mechanically ventilated intensive care patients. Crit Care Med 38: 2311-2318.

8 Singh R, Batra YK, Bharti N, Panda NB (2010) Comparison of propofol versus propofol-ketamine combination for sedation during spinal anesthesia in children: Randomized clinical trial of efficacy and safety. Paediatr Anaesth 20: 439-444.

9 Yamauchi M, Asano M, Watanabe M, Iwasaki S, Furuse S, et al. (2008) Continuous low-dose ketamine improves the analgesic effects of fentanyl patient-controlled analgesia after cervical spine surgery. Anesth Analg 107: 1041-1044.

\section{Conclusion}

This study concluded that using ketofol, dexmedetomidine or propofol for sedation of postoperative intubated and mechanically ventilated patients in the surgical ICU for $24 \mathrm{~h}$ was effective in maintaining Ramsay sedation score in the range of 2-4 for the patients who were sedated by ketofol or dexmedetomidine and 2-5 for the patients who were sedated by propofol without causing hemodynamic instability.

\section{Limitations of the Study}

More studies are recommended for the longer duration of mechanical ventilation.

\section{Conflicts of Interest}

The authors declare that there are no conflicts of interest.

10 Camu F, Vanlersberghe C (2002) Pharmacology of systemic analgesics. Best Pract Res Clin Anaesthesiol 16: 475-88.

11 Venn RM, Hell J, Grounds RM (2000) Respiratory effects of dexmedetomidine in the surgical patient requiring intensive care. Crit Care 4: 302-308.

12 Hall JE, Uhrich TD, Barney JA, Arain SR, Ebert TJ (2000) Sedative, amnestic, and analgesic properties of small-dose dexmedetomidine infusion. Anesth Analg 90: 699:705.

13 O'Connor M, Bucknall T, Manias E (2010) Sedation Management in Australian and New Zealand Intensive Care Units: Doctors' and Nurses' Practices and Opinions. Am J Crit Care 19: 285-295.

14 Hamimy IW, Zaghloul A, Mahmoud AAA (2012) The application of a new regimen for short term sedation in the ICU (ketofol)Case series. Egyptian J Anaesthesia 28: 179-182.

15 American Society of Anesthesiologists Task Force on Sedation Analgesia by Non-Anesthesiologists (2002) Practice guidelines for sedation and analgesia by non-anesthesiologists. Anesthesiology 96: 1004-1017.

16 Ramsay MA, Savege TM, Simpson BR, Goodwin R (1974) Controlled sedation with alphaxalone-alphadolone. $\mathrm{Br}$ Med J 22: 656-659.

17 Willman EV, Andolfatto G (2007) A Prospective evaluation of "ketofol" (ketamine/propofol combination for proceduralsedation and analgesia in the emergency department. Ann Emerg Med 49: 23-30.

18 Andolfatto G, Willman EV (2011) A prospective case series of single syringe ketamine-propofol (ketofol) for emergency department procedural sedation and analgesia in adults. Acad Emerg Med 3: 237-45.

19 Dal T, Sazak H, Tunc M, Sahin S, Yilmaz A (2014) A comparison ofketamine-midazolam and ketamine-propofol combinations used for sedation in the endobronchial ultrasound guided transbronchialneedle aspiration: a prospective, single blind, randomized study. J Thorac Dis 6: 742-751.

20 Yazdi GA, Ayatollahi V, Hashemi A, Behdad SH, Yazdi GE (2013) Effect of two different concentrations of propofol 
and'ketamine combinations (Ketofol) in pediatric patients under lumbar puncture or bone marrow aspiration. Iran J Ped Hematol Oncol 3: 187-192.

21 David H, Shipp J (2011) A randomised, controlled trial of ketamine/propofol versus propofol alone for emergency department procedural sedation. Ann Emerg Med 57: 435441.

22 Tosun Z, Aksu R, Guler G, Esmaoglu A, Akin A, et al. (2007) Propofol-ketamine vs propofol-fentanyl for sedation during pediatric upper gastrointestinal endoscopy. Pediatr Anesth 17: 983-988.

23 Loh G, Dalen D (2007) Low-dose ketamine in addition to propofol for procedural sedation and analgesia in the emergency department. Ann Pharmacother 41: 485-492.

24 Venn RM, Grounds RM (2001) Comparison between dexmedetomidine and propofol for sedation in the intensive care unit: patient and clinician perceptions. Br J Anaesth 87: 684-690.

25 Shah PN, Dongre V, Patil V, Pandya S, Mungantiwar A, et al.
(2014) Comparison of post-operative ICU sedation between dexmedetomidine and propofol in Indian population. Indian J Crit Care Med 18:291-296.

26 Corbett SM, Rebuck JA, Greene CM, Callas PW, Neale BW, et al. (2005) Dexmedetomidine does not improve patient satisfaction when compared to propofol during mechanical ventilation. Crit Care Med 33: 940-945.

27 Demiraran Y, Korkut E, Tamer A, Yorulmaz I, Kocaman B, et al. (2007) The comparison of dexmedetomidine and midazolam used for sedation of patients during upper endoscopy: A prospective, randomized study. Can J Gastroenterol 21: 25-29.

28 Jakob SM, Ruokonen E, Grounds RM, Sarapohja T, Garratt C, et al. (2012) Dexmedetomidine vs midazolam or propofol for sedation during prolonged mechanical ventilation: Two randomized controlled trials. JAMA 307: 1151-1160.

29 Srivastava VK, Agrawal S, Kumar S, Mishra A, Sharma S, et al. (2014) Comparison of dexmedetomidine, propofol and midazolam for short-term sedation in postoperatively mechanically Ventilated neurosurgical patients. J Clin Diagn Res 8: GC04-GC07. 